\title{
Effect of hypoxia-inducible factor 1- $\alpha$ on Survivin in colorectal cancer
}

\author{
XING-YE WU ${ }^{1,2}$, ZHONG-XUE FU ${ }^{1}$ and XUE-HU WANG ${ }^{1,2}$ \\ ${ }^{1}$ Department of General Surgery, and ${ }^{2}$ Key Laboratory of General Surgery, \\ The First Affiliated Hospital, Chongqing Medical University, Chongqing 400016, P.R. China
}

Received January 22, 2010; Accepted March 17, 2010

DOI: $10.3892 / \mathrm{mmr} 00000273$

\begin{abstract}
Colorectal cancer is a one of the most common malignancies. Hypoxia-inducible factor $1-\alpha(H I F 1-\alpha)$ and Survivin play important roles in tumor development; however, the literature currently contains few reports on the relationship between them in colorectal cancer. In this study, we investigated the effect of HIF1- $\alpha$ on Survivin in colorectal cancer. Immunohistochemical staining was used to detect the expression of HIF1- $\alpha$ and Survivin in colorectal cancer tissue from 32 patients. Colon adenocarcinoma SW480 cells were cultured under normoxia and hypoxic conditions, and the expression of HIF1- $\alpha$ and Survivin was detected by RT-PCR and Western blotting. We also silenced HIF1- $\alpha$ in order to detect the expression of Survivin and cell apoptosis. In an in vivo xenograft tumor model, the effect of HIF1- $\alpha$ on cancer development and Survivin was evaluated by the measurment of tumor volume and immunohistochemical analysis. Analysis revealed that HIF1- $\alpha$ (75\%) and Survivin (68.75\%) were both overexpressed in colorectal cancer, and that their expression was correlated. They were also expressed in SW480 cells under conditions of normoxia, and exhibited a significant increase in expression under hypoxic conditions. The inhibition of HIF1- $\alpha$ by RNA interference decreased the expression of Survivin and led to the apoptosis of the SW480 cell line. In the in vivo xenograft tumor model, the expression of HIF1- $\alpha$ and Survivin was decreased in the siHIF1- $\alpha$ group, and the tumor volume $\left(586.67 \pm 41.63 \mathrm{~mm}^{3}\right)$ was much smaller than that in the negative interference $\left(1374.67 \pm 85.87 \mathrm{~mm}^{3}\right)$ and salinetreated $\left(1382.80 \pm 28.42 \mathrm{~mm}^{3}\right)$ groups. Our results indicate that HIF1- $\alpha$ is an important regulator of Survivin expression and has great potential capacity for cancer therapeutics.
\end{abstract}

Correspondence to: Dr Zhong-Xue Fu, Department of General Surgery, The First Affiliated Hospital, Chongqing Medical University, Chongqing 400016, P.R. China

E-mail:fzx_md@hotmail.com

Key words: hypoxia-inducible factor 1- $\alpha$, Survivin, colorectal cancer

\section{Introduction}

Colorectal cancer (CRC) is the fourth most common type of cancer worldwide. In Asia, CRC has emerged as the second most common cancer (1). Although therapeutic innovations and enhanced education regarding lifestyle have greatly reduced the incidence of CRC, approximately $50 \%$ of CRC patients die from tumor metastasis and recurrence.

Hypoxia is a common feature in most solid human tumors and is associated with increased malignancy, suppressed differentiation and apoptosis, and increased multidrug resistance (2). The adaptive response to hypoxia is adjusted by a family of transcription factors; the most important member in this family is hypoxia-inducible factor $1-\alpha$ (HIF1- $\alpha$ ). The transcriptions of many genes that are critical for cellular function under hypoxic conditions are activated by HIF1- $\alpha$ (3). Survivin, a member of the inhibitor of apoptosis protein (IAP) family, is highly expressed in almost all types of human tumors and fetal tissues, but is barely detected in adult normal tissues $(4,5)$.

According to previous studies, the down-regulation of HIF1- $\alpha$ decreases the levels of Survivin expression in various types of cancer cells $(6,7)$. These data indicate that HIF1- $\alpha$ regulates the expression of Survivin. However, there are few studies reporting that Survivin expression is regulated by HIF1- $\alpha$ in CRC. In the present study, we comprehensively investigated the effect of HIF1- $\alpha$ on Survivin in CRC tumor tissue, in the CRC cell line SW480, and in an in vivo xenograft tumor model. Furthermore, HIF1- $\alpha$ was silenced in order to detect the expression of Survivin and cell apoptosis, as well as the impact on tumor growth in an in vivo xenograft tumor model.

\section{Materials and methods}

Tissue specimens. Tissue samples were obtained from patients with a pathological diagnosis of colorectal adenocarcinoma as determined by two pathologists. Patients underwent surgery at the Department of Gastrointestinal Surgery, The First Affiliated Hospital, Chongqing Medical University, during the period from March 2009 to May 2009. Thirty-two CRC patients participated in the study. The patient population included 13 males and 19 females with an average age of 61 years (range 38-75 years). All of the patients had moder- 
ately differentiated cancer. TNM staging indicated that 20 cases were in stage I-II and 12 cases in stage III according to the CRC staging standard by the International Union Against Cancer (UICC). No patients had undergone preoperative radiotherapy or chemotherapy. The principle committee of the First Affiliated Hospital of Chongqing Medical University authorized this research.

Cell lines and cell culture. The human colon adenocacinoma cell line SW480 was obtained from the Institute of Biochemistry and Cell Biology (Shanghai, China), and was cultured in RPMI-1640 medium (Invitrogen) supplemented with $10 \%$ (vol/vol) fetal bovine serum (Invitrogen) at $37^{\circ} \mathrm{C}$ in a humidified incubator containing $5 \% \mathrm{CO}_{2}$. To attain and control hypoxic conditions, cells were placed in a three-chamber air incubator (Thermo) and flushed with a gas mixture of 5\% $\mathrm{CO}_{2}-95 \% \mathrm{~N}_{2}$ at $37^{\circ} \mathrm{C}$. The final $\mathrm{pO}_{2}$ value of the medium was consistently measured at a range of $0.5-1 \%$. A scheme protocol of $1 \mathrm{~h}$ hypoxia interrupted by 30-min periods of reoxygenation was used to simulate the tumor hypoxic environment (8).

Construction of HIFl- $\alpha$ shRNA expression plasmid and stable transfection. Two pairs of short hairpin RNA (shRNA) targeting HIF1- $\alpha$ (GeneBank accession NM_001530) were constructed and subcloned into the pGenesil-11 plasmid. The sequence was AACTAACTGGACACAGTGTGT and AAA GCCACTTCGAAGTAGTGC. None of these sequences were homologous with any human coding gene according to a BLAST analysis. The shRNA was constructed into the pGenesil-11 plasmid by Genesil Biotechnology Co., Ltd. (Wuhan, China), and a black plasmid served as the negative control. These were named SW480siHIF1- $\alpha$ and SW480N, respectively. In the blank control group, PBS was used in place of the plasmid. Cells were transfected with Lipofectin 2000 (Invitrogen) according to the manufacturer's protocol.

Immunohistochemistry. Tumors were fixed in $4 \%$ paraformaldehyde and processed through a series of increasing ethanol concentrations for paraffin embedding. Sections $(4-\mu \mathrm{m})$ were obtained, deparaffinized in xylene, rehydrated and treated with $3 \%$ hydrogen peroxide for $20 \mathrm{~min}$, and incubated with blocking serum at room temperature for 30 min. Immunohistochemistry was carried out using rabbit anti-HIF1- $\alpha$ and Survivin (Santa Cruz) primary polyclonal antibodies, and subsequently with a secondary antibody (goat anti-rabbit) (Santa Cruz). The expression of HIF1- $\alpha$ and Survivin was visualized by chromogen 3,3-diaminobenzidine immunolabeling. Finally, the sections were counterstained with hematoxylin.

RT-PCR analysis. RT-PCR was used for the analysis of HIF1- $\alpha$ and Survivin mRNA with GAPDH as an internal control. Total RNA was extracted from the cells using RNAiso reagent (Takara Biotechnology CO., Ltd., Dalian, China) as recommended by the manufacturer. Primers for HIF1- $\alpha$ were: forward 5'-AGA AAC CAC CTA TGA CCT GC-3', reverse 5'-TGA GTT TCA ACC CAG ACA TA-3'. Primers for Survivin were: forward 5'-GAC CAC CGC ATC TCT ACA TTC-3', reverse 5'-GTT CTT GGC TCT TTC TCT GTCC-3' (9). The GAPDH primers were: forward 5'-ACC ACA GTC
CAT GCC ATC AC-3', reverse 5'-TCC ACC ACC CTG TTG CTG TA-3' (9). Reactions were performed in accordance with the standard protocol. One step RT-PCR (Takara) was performed at $50^{\circ} \mathrm{C}$ for $30 \mathrm{~min}$ and $2 \mathrm{~min}$ at $94^{\circ} \mathrm{C}$, followed by 27 cycles of $30 \mathrm{sec}$ at $94^{\circ} \mathrm{C}, 30 \mathrm{sec}$ at $60^{\circ} \mathrm{C}$ and $45 \mathrm{sec}$ at $72^{\circ} \mathrm{C}$. The products were separated by electrophoresis in $3 \%$ agarose and visualized with ethidium bromide.

Western blot analysis. Cells from each group were harvested, and the protein extracts were separated using sodium dodecyl sulfate-polyacene gel electrophoresis and transferred onto nitrocellulose membranes. The membranes were then blocked with the primary polyclonal antibodies against HIF1- $\alpha$, Survivin and $\beta$-actin (rabbit anti-human) (Santa Cruz) at $4^{\circ} \mathrm{C}$ overnight. After being washed with TBS containing $0.05 \%$ Tween-20, the membranes were incubated with a secondary antibody (goat anti-rabbit) for $2 \mathrm{~h}$ and were then visualized by a chemiluminescence system according to the manufacturer's instructions.

Flow cytometric evaluation. Apoptosis of the cells was determined by flow cytometry using the Annexin V-FITC Apoptosis Detection kit (KeyGen, China) according to the manufacturer's instructions. Briefly, the cells were washed twice with cold PBS and resuspended in binding buffer at a concentration of $1 \times 10^{5}$ cells $/ \mathrm{ml}$. They were then incubated with $5 \mu \mathrm{l}$ of Annexin V-FITC and $5 \mu \mathrm{l}$ of propidium iodide for $15 \mathrm{~min}$ at room temperature in the dark. Finally, $400 \mu \mathrm{l}$ of binding buffer was added, and cells were analyzed by flow cytometry.

Electron microscope detection. Cells were collected and washed with PBS three times and fixed in $4 \%$ glutaraldehyde at $4^{\circ} \mathrm{C}$. The sample preparation was completed by the Laboratory of Electron Microscopy of Chongqing Medical University. The observation instrument was the HITACHI 7500.

Animal studies. Five-week-old female BALBC/C nude mice were obtained from the Laboratory Animal Center of Chongqing Medical University and were maintained in specific pathogen-free units under isothermal conditions. All experimental procedures were carried out in accordance with the National Institute of Health Guide for the Care and Use of Laboratory Animals. SW480 cells $\left(5 \times 10^{6}\right)$ suspended in $0.1 \mathrm{ml}$ serum-free medium were implanted subcutaneously into the flank of the nude mice. When the tumor size reached $100 \mathrm{~mm}^{3}$, the mice were randomly divided into 3 groups $(\mathrm{n}=6)$ (9). According to the method of Filleur et al (10), the mice were intraperitoneally injected with $3 \mu 1$ of siRNA suspended in $50 \mu \mathrm{l}$ saline or $50 \mu \mathrm{l}$ saline alone. Tumors were monitored by measuring the tumor volume with a caliper. Tumor volume was calculated by the formula: $\mathrm{V}\left(\mathrm{mm}^{3}\right)=$ length $\mathrm{x}$ width $2 / 2$. After 24 days, the tumors were harvested for immunohistochemistical staining. Subsequent steps were identical to those described in 'Immunohistochemistry'.

Statistical analysis. Data were represented as the mean \pm SD. The t-test, one-way ANOVA and Spearman rank correlation were carried out using SPSS 10.1 statistical software. Statistical significance was assumed at values of $\mathrm{p}<0.05$. 

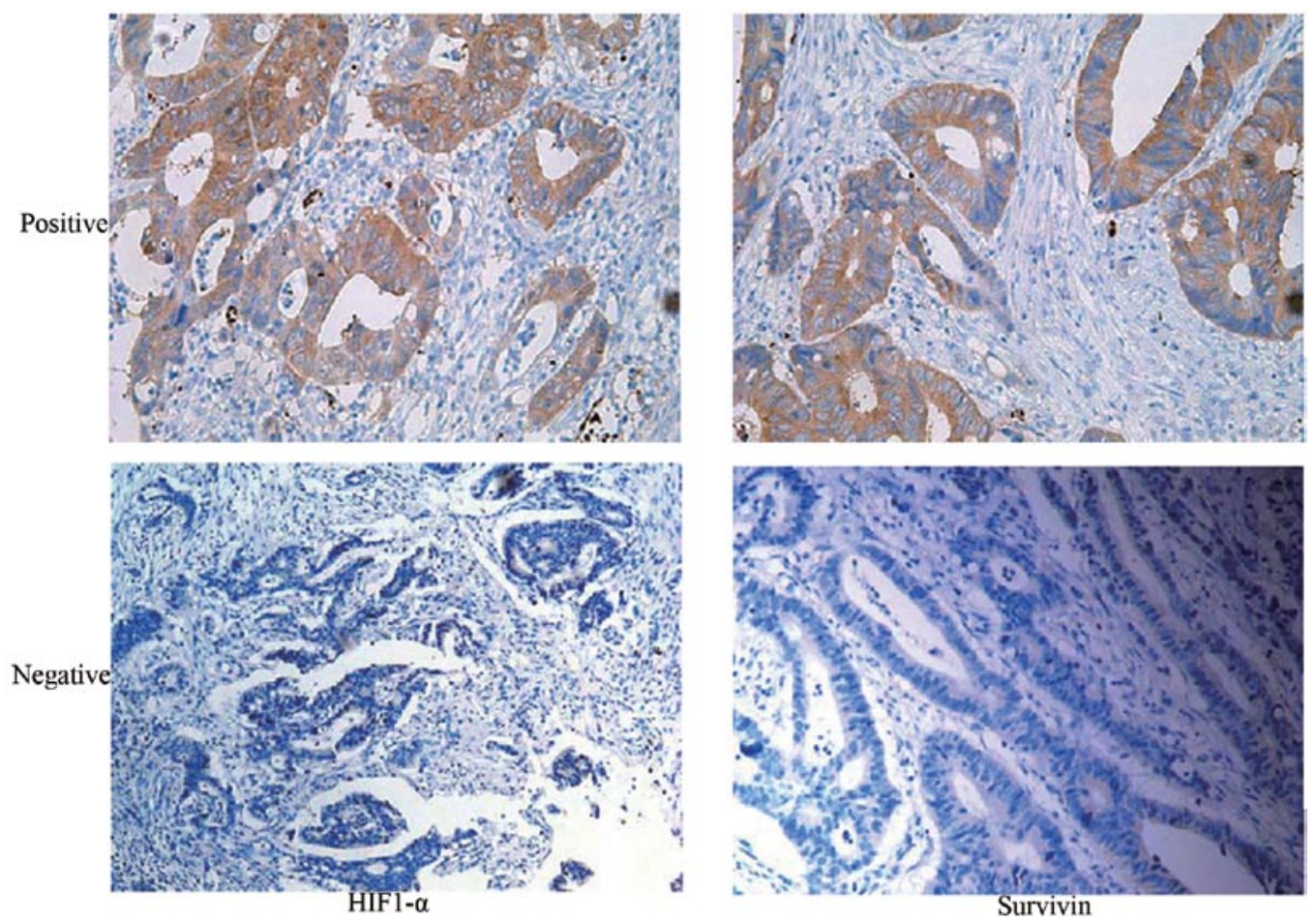

Figure 1. Expression of HIF1- $\alpha$ and Survivin protein in CRC tissue samples (x200). HIF1- $\alpha$ and Survivin proteins were expressed mainly in the cytoplasm. Seventy-five percent (23/32) of the CRC tissue samples were positive for HIF1- $\alpha$ staining, and 68.75\% (22/32) for Survivin staining.

\section{Results}

Expression of HIFl- $\alpha$ and Survivin in CRC tissues. HIF1- $\alpha$ and Survivin proteins were detected in paraffin-embedded human CRC tissue sections using immunohistochemistry, and were found to be predominantly expressed in the cytoplasm of the tumor cells (Fig. 1). The positive rate of HIF1- $\alpha$ and Survivin in the CRC samples was $75.00 \%$ (23/32) and 68.75\% (22/32), respectively. Spearman correlation analysis showed a correlation between the expression of HIF1- $\alpha$ and the expression of Survivin in the CRC tissue samples ( $\mathrm{rs}=0.478$, $\mathrm{p}=0.006$ ) (Table I).

Hypoxia induces expression of HIF1- $\alpha$ and Survivin. SW480 cells were incubated under normoxia and hypoxic conditions, and the expression of HIF1- $\alpha$ and Survivin was detected by RT-PCR (Fig. 2A) and Western blot analysis (Fig. 2B). As shown in Fig. 2, the expression of HIF1- $\alpha$ and Survivin was increased significantly in the hypoxic group as compared to the expression in the normoxia group $(\mathrm{p}<0.01)$.

Decrease in HIFl- $\alpha$ expression leads to reduced Survivin expression. The expression levels of HIF1- $\alpha$ mRNA were detected by RT-PCR on days 3, 7 and 15 in each group. In the SW480siHIF1- $\alpha$ group, HIF1- $\alpha$ expression was eliminated, particularly on day 7 , whereas the expression level of HIF1- $\alpha$ mRNA in the SW480N and blank control groups did not change (Fig. 3A). On day 7, HIF1- $\alpha$ protein expression analyzed by Western blotting (Fig. 3B) showed a result consistent with results from RT-PCR. As shown in Fig. 3C and D, the mRNA and protein expression levels of Survivin on day 7 in the SW480siHIF1- $\alpha$ group were significantly decreased
Table I. Correlation of HIF1- $\alpha$ and Survivin expression in CRC tissue samples.

$$
\text { Expression of Survivin }
$$

Expression of HIF1- $\alpha$ Positive $(n=22) \quad$ Negative $(n=10) \quad$ P-value

\begin{tabular}{lrrr}
\hline Positive $(n=23)$ & 19 & 4 & 0.006 \\
Negative $(n=9)$ & 3 & 6 & \\
\hline
\end{tabular}

compared with the levels in the SW480N and black control groups $(\mathrm{p}<0.01)$.

HIF1- $\alpha$ silencing induces apoptosis. As shown in Fig. 4, transfection with HIF1- $\alpha$ shRNA markedly increased the apoptotic cell populations in the SW480 cells, as demonstrated by flow cytometric analysis. The apoptotic rate in the SW480siHIF1- $\alpha$ group $(20.30 \pm 1.07 \%)$ showed high statistical significance compared with the SW480N $(4.26 \pm 0.27 \%)$ and black control $(3.40 \pm 0.29 \%)$ groups (Fig. $4 \mathrm{~A})(\mathrm{p}<0.01)$. In the SW480siHIF1- $\alpha$ group, the surface of the cells exhibited many cytoplasmic protrusions, and high electron density condensation nuclei and apoptotic bodies were noted upon electron microscope detection. There were no obvious morphological changes characteristic of apoptosis in the SW480N and black control groups (Fig. 4B).

Effects of HIF1- $\alpha$ on Survivin in the in vivo xenograft tumor model. To determine the effect of HIF1- $\alpha$ on Survivin expression and CRC tumor growth in vivo, SW480 cells suspended in serum-free medium were subcutaneously 
A

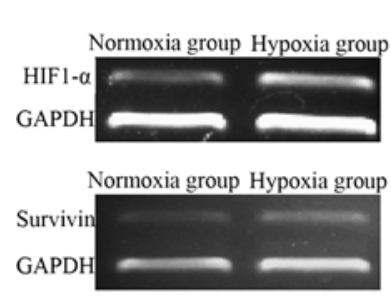

B

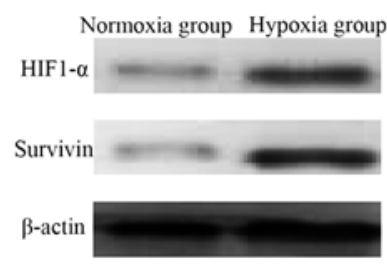

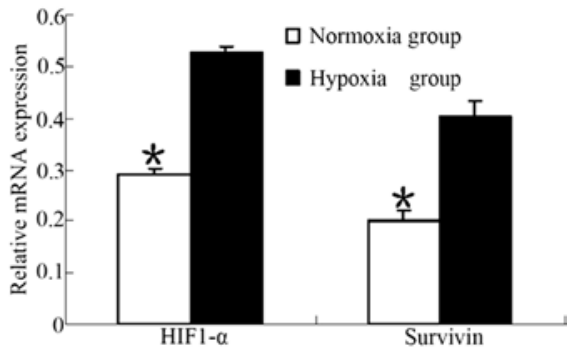

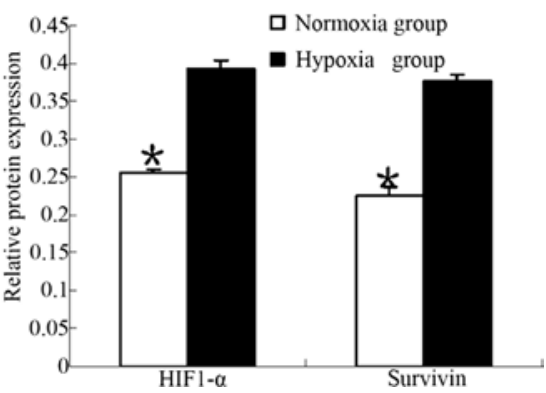

Figure 2. Expression of HIF1- $\alpha$ and Survivin under normoxia and hypoxic conditions. SW480 cells were cultured under normoxia and hypoxic conditions. (A) Expression of HIF1- $\alpha$ and Survivin mRNA was significantly increased in the hypoxic compared to the normoxia group ("p<0.01). (B) Protein expression showed similar results $($ " $\mathrm{p}<0.01)$

A

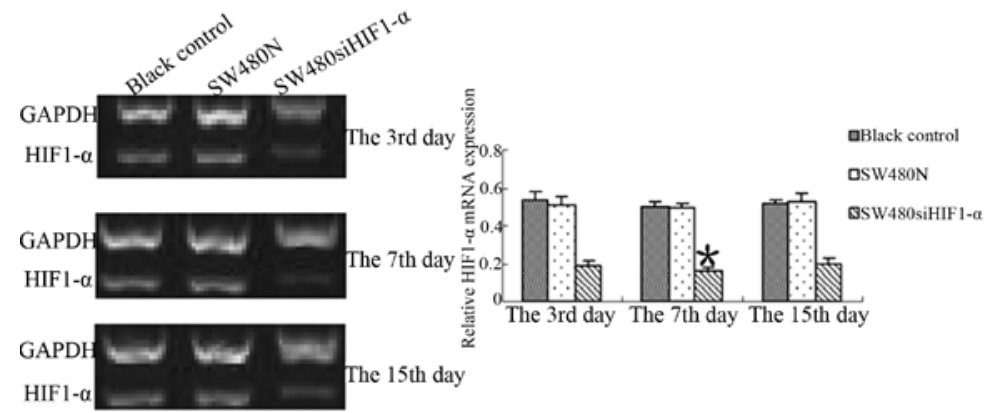

B

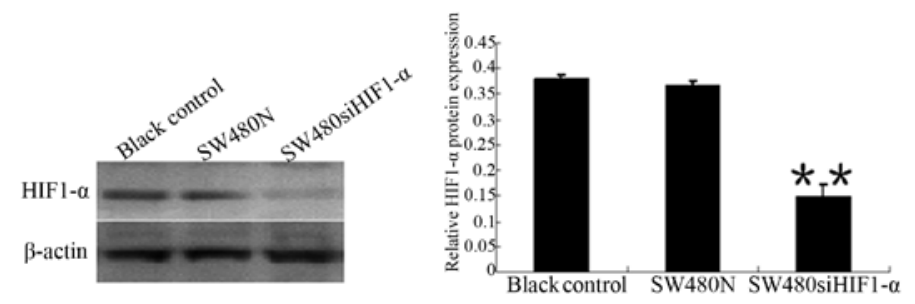

C

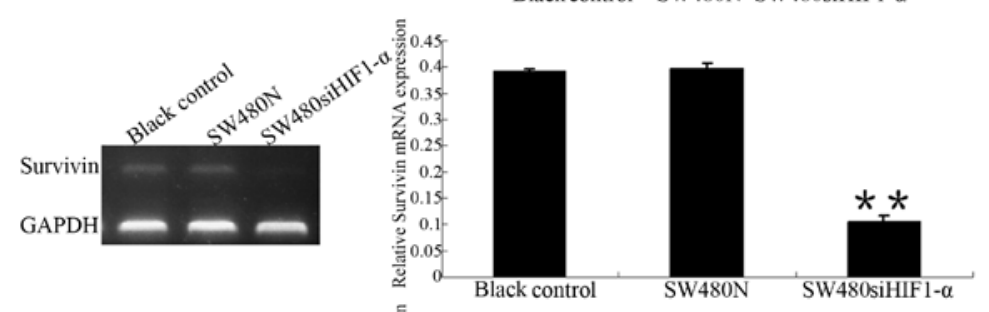

D

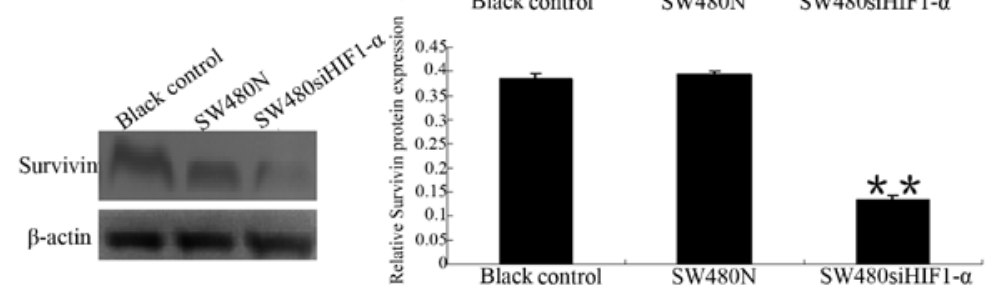

Figure 3. Downregulated HIF1- $\alpha$ expression leads to decreased Survivin expression in SW480 cells. (A) Expression of HIF1- $\alpha$ mRNA was significantly decreased in the SW480siHIF1- $\alpha$ group, particularly on day 7 ("p $<0.05$ vs. other groups). (B) Western blot detection of HIF1- $\alpha$ protein expression on day 7 . SW480siHIF1- $\alpha$ induced a marked reduction in HIF1- $\alpha$ synthesis $\left({ }^{* * *} \mathrm{p}<0.01\right)$. (C) Survivin mRNA and (D) Survivin proteins were decreased by the silencing of HIF1- $\alpha$ on day $7\left({ }^{* *} \mathrm{P}<0.01\right)$. 
A
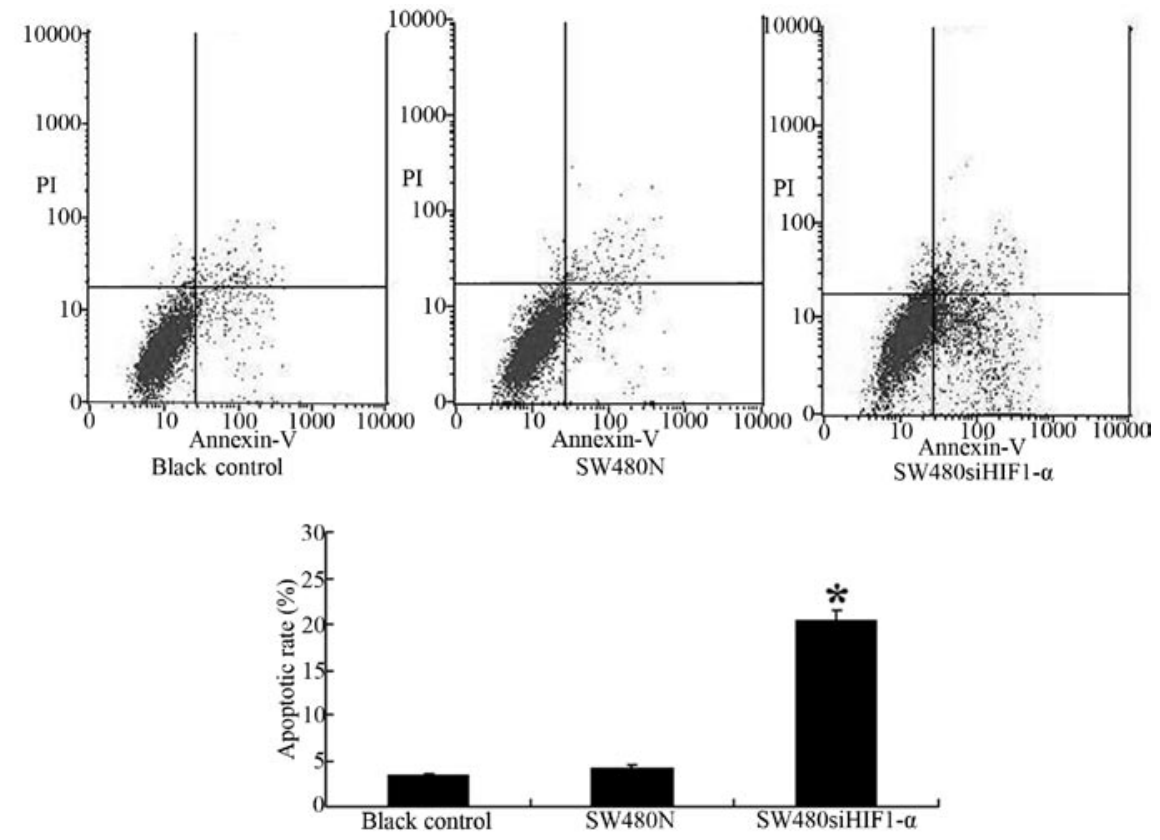

B

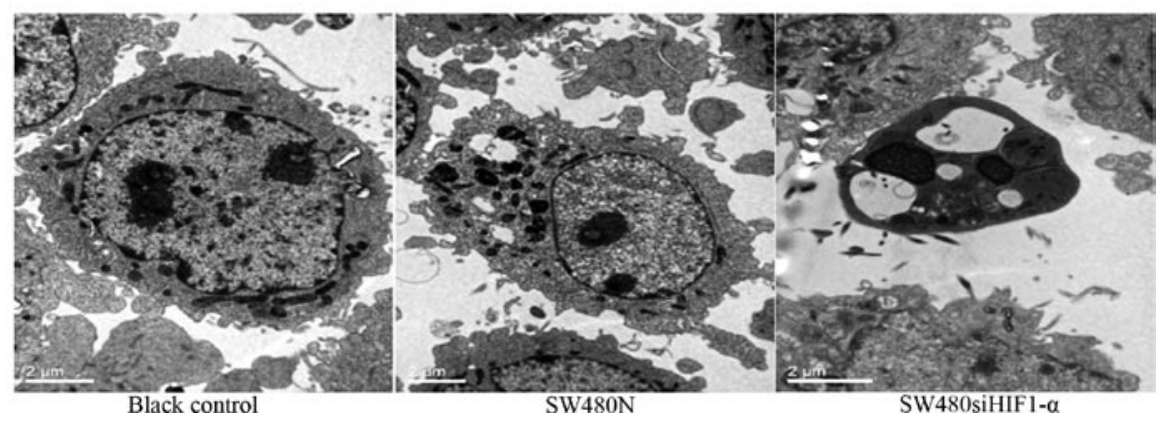

Figure 4. Cell apoptosis detected by flow cytometry and electron microscopy. (A) The apoptotic rate was markedly higher in the SW480siHIF1- $\alpha$ group compared to the SW480N and black control groups ( $\left.{ }^{*} \mathrm{P}<0.01\right)$. (B) In theSW480siHIF1- $\alpha$ group, the formation of apoptotic bodies was noted upon electron microscope detection.

implanted into nude mice, and siRNA was intraperitoneally injected. Twenty-four days later, the mice were sacrificed and the tumors were resected. The tumor volume of the siHIF1- $\alpha$ group was $586.67 \pm 41.63 \mathrm{~mm}^{3}$, which was much smaller than that of the negative interference $\left(1374.67 \pm 85.87 \mathrm{~mm}^{3}\right)$ and saline-treated $\left(1382.80 \pm 28.42 \mathrm{~mm}^{3}\right)$ groups (Fig. 5A). HIF1- $\alpha$ and Survivin protein expression was analyzed in the in vivo xenograft tumor model by immunohistochemistry. As shown in Fig. 5B, HIF1- $\alpha$ and Survivin proteins showed a marked reduction in the siHIF1- $\alpha$ group as compared with the negative interference and the saline groups.

\section{Discussion}

Hypoxia is considered to be one of the tumor microenvironment factors favoring tumor cell survival and resistance to chemotherapy and radiotherapy (11). HIF1- $\alpha$ is a master regulator of the transcriptional response of cancer cells to oxygen deprivation. Since its discovery in the early 1990s, HIF1- $\alpha$ has rapidly attracted attention due to its involvement in tumor metabolism, angiogenesis and metastasis, and its potential role as a cancer therapeutic target (12).

HIF1- $\alpha$ expression has been detected in the majority of solid tumors examined, including brain, bladder, breast, colon, ovarian, pancreatic, renal and prostate cancer, whereas no expression has been detected in surrounding normal tissue or in benign tumors. Up-regulation of HIF1- $\alpha$ increases HIF1 transcription factor activity and promotes tumor growth, whereas loss of HIF1- $\alpha$ activity dramatically decreases angiogenesis, tumor growth and energy metabolism. Clinically, HIF1- $\alpha$ overexpression was found to be a biomarker of highly aggressive disease and is associated with poor patient prognosis and treatment failure in various types of cancer (13). Survivin, the smallest protein of the IAP family, is weakly or not at all expressed in normal tissues, but is overexpressed in fetal tissues and many tumors. This overexpression was also found to be correlated with poor patient prognosis in medulloblastoma and breast cancer (14-17). HIF1- $\alpha$ and Survivin were found to be overexpressed in non-small-cell lung cancer, and their expression levels were demonstrated to be correlated (18). In this study, HIF1- $\alpha$ and Survivin were highly expressed in CRC tissue. Correlation analysis showed that the expression of HIF1- $\alpha$ was positively correlated with that of Survivin.

Recently, it was found that tumor-specific expression of Survivin is increased by hypoxia (19). We also found that the expression of HIF1- $\alpha$ and Survivin mRNA or protein in cells was significantly increased under hypoxic conditions. To further confirm that Survivin is induced by HIF1- $\alpha$, RNA 
A
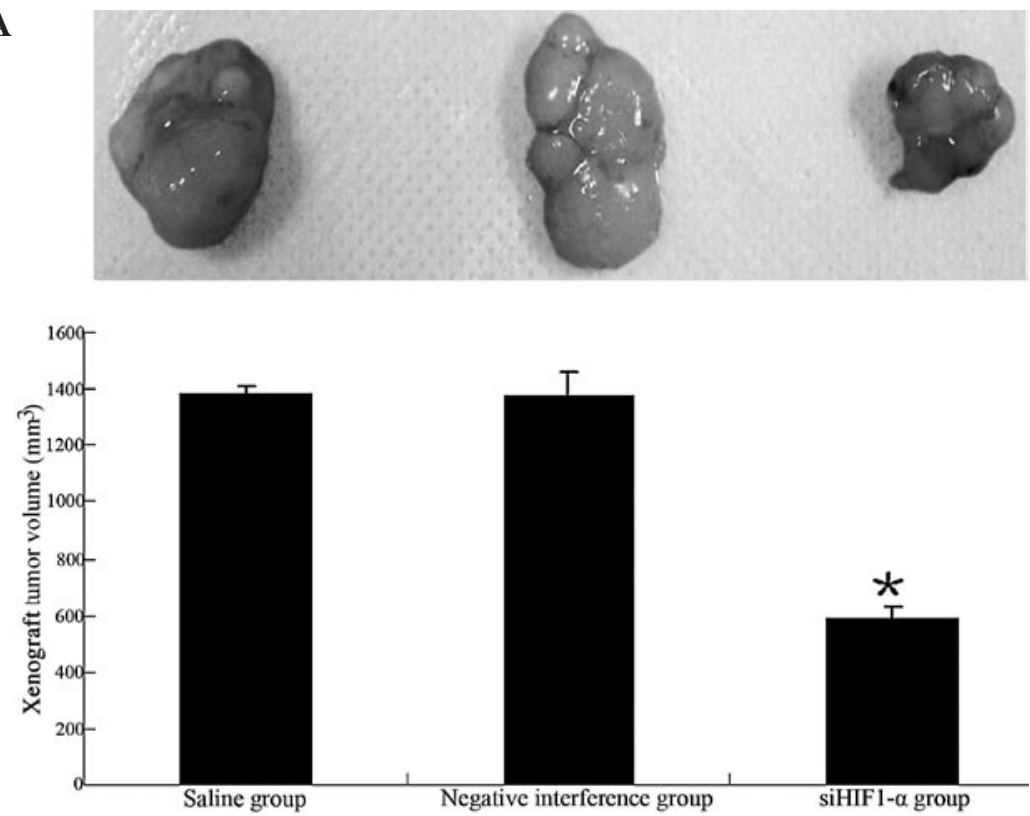

B

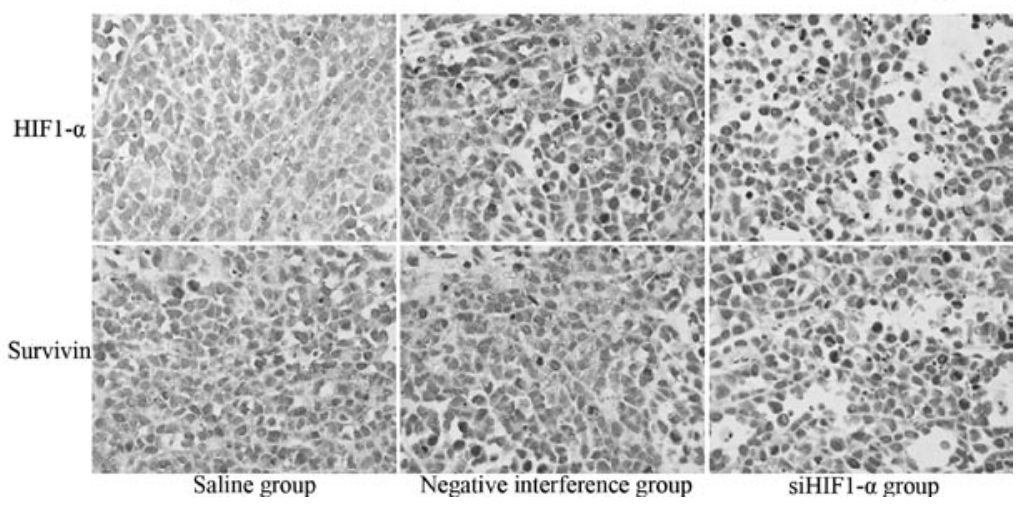

Figure 5. Effects of RNA interference of HIF1- $\alpha$ on tumor growth and Survivin expression in a nude mice xenograft tumor model. (A) In the negative interference and saline groups, tumor volume was larger than the tumor volume in the siHIF1- $\alpha$ group $\left({ }^{*} \mathrm{P}<0.01\right)$. (B) As evident from the immunohistochemistry of proteins from the xenograft tumors, the expression of Survivin protein was inhibited by the silencing of HIF1- $\alpha$ (x200)

interference was used to decrease the expression of HIF1- $\alpha$ in SW480 cells. We found that this decrease was significantly correlated with the reduced mRNA and protein expression of Survivin. In an in vivo xenograft tumor model, the decrease in Survivin protein expression was associated with low expression of HIF1- $\alpha$ protein. This suggests that HIF1- $\alpha$ may be an important factor in the regulation of Survivin expression.

Notably, we found that the cells in the SW480siHIF1- $\alpha$ group had a higher apoptotic rate than those in the SW480N and black control groups, and morphological changes characteristic of apoptosis were noted. A possible explanation is that the most important function of Survivin in tumors is the inhibition of tumor cell apoptosis (6). In rectal carcinoma patients, Survivin expression was inversely increased. leading to lower levels of apoptosis and a higher risk of local tumor recurrence (20). Thus, inhibition of HIF1- $\alpha$ gene expression led to a decrease in the expression of Survivin, and subsequently the anti-apoptosis ability of tumor cells was decreased.

In the in vivo xenograft tumor model, siRNA was intraperitoneally injected. Twenty-four days later, the tumor volume of the siHIF1- $\alpha$ group was much smaller than that in the negative interference and saline groups. Silencing of HIF1- $\alpha$ facilitated tumor cell apoptosis and inhibited tumor growth in this study. However, whether or not HIF1- $\alpha$ is a good target for the development of cancer therapeutics requires further investigation. Since it has a large number of downstream genes, HIF1- $\alpha$ may play a complex role in cancer biology (20). It was recently demonstrated using DNA microarrays that more than $2 \%$ of all human genes in arterial endothelial cells are directly or indirectly regulated by HIF1- $\alpha$ (21). To date, a comprehensive understanding of this has not been achieved. Therefore, the determination of which downstream genes participate in cancer development and the identification of their functions in tumors under hypoxic conditions warrant further research.

In conclusion, our experimental results demonstrated that HIF1- $\alpha$ and Survivin are highly expressed in CRC tissue and colon adenocarcinoma SW480 cells, and that the expression of these proteins is correlated. Additionally, we showed that hypoxia induced the expression of HIF1- $\alpha$ and Survivin. Furthermore, the inhibition of HIF1- $\alpha$ resulted in the attenuation of Survivin expression. HIF1- $\alpha$ may therefore be an key factor involved in the regulation of Survivin expression. The inhibition of HIF1- $\alpha$ may be an important and feasible therapeutic target for colorectal carcinoma. 


\section{Acknowledgements}

This study was supported by grants from the 2009 Annual Medical Research Projects of Chongqing Municipal Health Bureau (no. 2009-1-49), the Key Project of Chongqing Medical University (no. XBZD200706) and the National Natural Science Foundation of China (nos. 30772547). We thank the Key Laboratory of Ophthalmology, Chongqing Medical University, for equipment support.

\section{References}

1. Sung JJ, Choi SY, Chan FK, Ching JY, Lau JT and Griffiths S: Obstacles to colorectal cancer screening in Chinese: a study based on the health belief model. Am J Gastroenterol 103: 974-981, 2008

2. Wu XZ: New strategy of antiangiogenic therapy for hepatocellular carcinoma. Neoplasma 55: 472-481, 2008.

3. Hockel M, Schlenger K, Aral B, Mitze M, Schaffer U and Vaupel P: Association between tumor hypoxia and malignant progression in advanced cancer of the uterine cervix. Cancer Res 56: 4509-4515, 1996.

4. Deveraux QL and Reed JC: IAP family proteins - suppressors of apoptosis. Genes Dev 13: 239-252, 1999.

5. Ambrosini G, Adida C and Altieri DC: A novel anti-apoptosis gene, survivin, expressed in cancer and lymphoma. Nat Med 3 : 917-921, 1997.

6. Peng XH, Karna P, Cao Z, Jiang BH, Zhou M and Yang L: Cross-talk between epidermal growth factor receptor and hypoxia-inducible factor-1alpha signal pathways increases resistance to apoptosis by up-regulating survivin gene expression. J Biol Chem 281: 25903-25914, 2006.

7. Chang Q, Qin R, Huang T, Gao J and Feng Y: Effect of antisense hypoxia-inducible factor lalpha on progression, metastasis, and chemosensitivity of pancreatic cancer. Pancreas 32: 297-305, 2006.

8. Martinive P, Defresne F, Bouzin C, et al: Preconditioning of the tumor vasculature and tumor cells by intermittent hypoxia: implications for anticancer therapies. Cancer Res 66: 11736-11744, 2006.
9. Shen W, Wang CY, Wang XH and Fu ZX: Oncolytic adenovirus mediated Survivin knockdown by RNA interference suppresses human colorectal carcinoma growth in vitro and in vivo. J Exp Clin Cancer Res 28: 81, 2009.

10. Filleur S, Courtin A, Ait-Si-Ali S, et al: SiRNA-mediated inhibition of vascular endothelial growth factor severely limits tumor resistance to antiangiogenic thrombospondin-1 and slows tumor vascularization and growth. Cancer Res 63: 3919-3922, 2003.

11. Toffoli S and Michiels C: Intermittent hypoxia is a key regulator of cancer cell and endothelial cell interplay in tumours. FEBS J 275: 2991-3002, 2008.

12. Melillo G: Inhibiting hypoxia-inducible factor 1 for cancer therapy. Mol Cancer Res 4: 601-605, 2006.

13. Powis G and Kirkpatrick L: Hypoxia inducible factor-1 alpha as a cancer drug target. Mol Cancer Ther 3: 647-654, 2004.

14. Haberler C, Slave I, Czech T, et al: Histopathological prognostic factors in medulloblastoma: high expression of survivin is related to unfavourable outcome. Eur J Cancer 42: 2996-3003, 2006.

15. Sohn DM, Kim SY, Baek MJ, Lim CW, Lee MH, Cho MS and Kim TY: Expression of survivin and clinical correlation in patients with breast cancer. Biomed Pharmacother 60: 289-292, 2006.

16. Akyürek N, Memiş L, Ekinci O, Köktürk N and Oztürk C: Survivin expression in pre-invasive lesions and non-small cell lung carcinoma. Virchows Arch 449: 164-170, 2006.

17. Rödel F, Hoffmann J, Distel L, et al: Survivin as a radioresistance factor, and prognostic and therapeutic target for radiotherapy in rectal cancer. Cancer Res 65: 4881-4887, 2005.

18. Chen YQ, Zhao CL and Li W: Effect of hypoxia-inducible factorlalpha on transcription of survivin in non-small cell lung cancer. J Exp Clin Cancer Res 28: 29, 2009.

19. Yang L, Cao Z, Li F, Post DE, van Meir EG, Zhong H and Wood C: Tumor-specific gene expression using the Survivin promoter is further increased by hypoxia. Gene Ther 11: 1215-1223, 2004

20. Semenza GL: Targeting HIF-1 for cancer therapy. Nat Rev Cancer 3: 721-732, 2003.

21. Manalo DJ, Rowan A, Lavoie T, et al: Transcriptional regulation of vascular endothelial cell responses to hypoxia by HIF-1. Blood 105: 659-669, 2005. 